\title{
Sustainable irrigation in the Yanqi basin, China
}

\author{
P. Brunner ${ }^{1}$, W. Kinzelbach ${ }^{1}$, W. P. Li $^{2} \&$ X. G. Dong ${ }^{3}$ \\ ${ }^{1}$ Institute of Environmental Engineering (IFU), ETH Zurich, Switzerland \\ ${ }^{2}$ China University of Geosciences (Beijing), Haidian District, Beijing, \\ China \\ ${ }^{3}$ Xinjiang Agricultural University, Urumqi, China
}

\begin{abstract}
The Yanqi basin, located in Xinjiang Province, China is a typical example of an area suffering from soil salinization induced by irrigation. The application of stream water without adequate drainage has raised the groundwater table in recent years, causing significantly increased groundwater evaporation (phreatic evaporation) and triggering soil salinization. The Yanqi basin has abundant groundwater resources recharged by the rivers outside the irrigated area. Groundwater from the second aquifer layer could be used for irrigation purposes as the water quality is high. If a part of the irrigation water directly drawn from the rivers is substituted by river water pumped indirectly from the aquifer, the groundwater table will drop and the process of salinization will be slowed down. However, abstraction from the second layer does include a risk. If the groundwater table in the first layer is lowered due to the abstraction of water in the second layer, water infiltrating from the (saline) first layer to the second layer continuously imports salt into the second aquifer layer. A coupled model of ground and surface water flow was set up to determine the resulting salt concentration of the aquifer system as well as of the irrigation water. Moreover, the ideal amount of groundwater applied to irrigation was determined by using the model. The model was constructed and verified by using spatially distributed input data derived from remote sensing. The simulations revealed that around $50 \%$ of the phreatic evaporation is related to irrigation. Moreover, the simulations showed that for every $\mathrm{m}^{3}$ of groundwater pumped, phreatic evaporation is lowered by $0.75 \mathrm{~m}^{3}$, and that the salinized area is reduced by $50 \mathrm{~km}^{2}$. Besides showing the changes in the overall water balance, the simulations proved that the steady state salt concentration in the aquifer system and in the irrigation water remains low, even if groundwater from the second layer is abstracted.
\end{abstract}

Keywords: remote sensing, groundwater modelling, model calibration, DEM, evapotranspiration. 


\section{Introduction}

Salinization occurs naturally (primary salinization) or due to human activities (secondary salinization). Comprehensive overviews covering most of the causes, consequences and possibilities to tackle the problem of salinization can be found in Hillel [6]; Jakeman et al. [7]; Richards [10], just to mention a few examples. The consequences of soil salinity have accompanied societies that rely on irrigated agriculture throughout history. Various historical and present examples are described by Hillel [5]. Different forms of irrigation and their influence on salinization have widely been studied (e.g. Hillel [4]; Rhoades et al. [9]).

A shallow depth to groundwater is one of the main causes of soil salinity: As the groundwater table rises, salts stored in the unsaturated zone are dissolved. If the groundwater table has reached a critical depth (extinction depth), groundwater can evaporate directly via capillary rise (phreatic evaporation). Salts dissolved in the groundwater accumulate at the soil surface as the groundwater evaporates. This irrigation induced soil salinization is observed in many semiarid countries. A typical example is the Yanqi basin. The ongoing irrigation without adequate drainage has continuously raised the groundwater table and caused a soil salinization in the root zone.

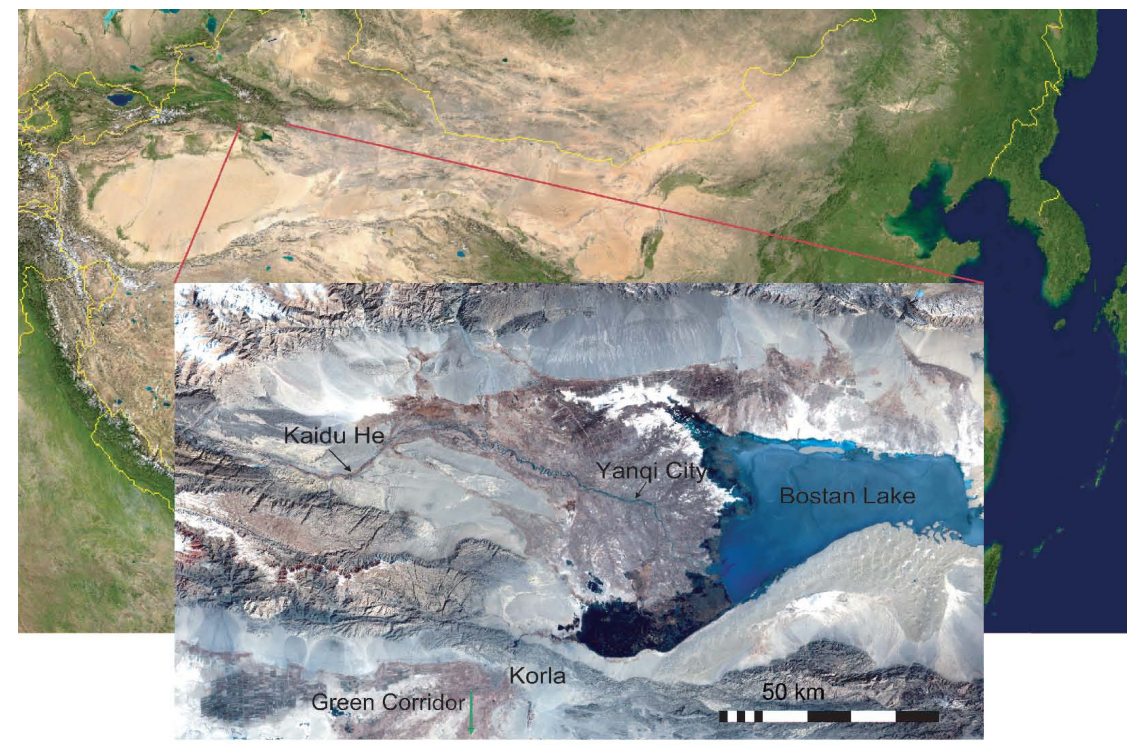

Figure 1: Location of the Yanqi basin.

\section{Project area}

The project area is the Yanqi basin, located in the far west of China (see figure 1). The intensive irrigation agriculture has led to several environmental problems in the Yanqi basin, especially soil salinization. According to Dong 
et al. [3], $60 \%$ of the irrigated area exhibited a depth to groundwater smaller than $2 \mathrm{~m}$ in the year 2000. Agriculture is entirely based on the water drawn from the Kaidu River. The distribution system of irrigation water is inefficient; a large amount of water is wasted both through inadequate supply systems and poor irrigation practices. In the basin itself, agricultural production can still be maintained at a profitable level. This is only possible as surface water resources are abundant and salinization can be controlled by over-irrigation. But the impact for downstream riparians, including both agricultural and natural systems, is high: Surface water resources are not available to the required extent and the salt concentration has increased due to the high evaporation losses upstream, limiting the productivity of the affected systems.

The lowest point of the basin is Bostan Lake. Its main inflow is the Kaidu River. Bostan Lake with over $1000 \mathrm{~km}^{2}$ of open water surface is the largest fresh water lake in Xinjiang. The deepest point is only $17 \mathrm{~m}$ below the water surface. The outflow of the lake, the Kongque River, is regulated by a pumping station. The lake is surrounded by salt marshes. The Kongque River supplies the so called Green Corridor with water.

The Yanqi basin features large groundwater resources recharged by the rivers flowing through it. The stratigraphy along the mountain range is mainly composed of moraine and glaciofluvial sediments, such as loam and gravel (Lin et al., [8]. These sediments (also called Gobi-formation) feature a high hydraulic permeability. Between the surrounding mountains and the central area of the Yanqi basin, these sediments form a weakly heterogeneous aquifer down to the bedrock. The infiltration of river water occurs within this formation. The stratigraphy in the central area of the Yanqi basin is complex. It is the only area where soil could develop and agriculture is possible. The aquifer in the central area of the Yanqi basin can be divided into four layers separated by relatively thin but nearly impermeable silt layers. The hydraulic conductivity of the second aquifer layer is over a magnitude larger than the hydraulic conductivities of the other layers. The high hydraulic conductivity of the second layer allows to abstract groundwater. The confined layers are all connected to the Gobiformation. The water of the confined layers is therefore of good quality and can be used for irrigation purposes. The large amount of salt deposited over time in the first layer, however, significantly reduces its water quality. The salt deposited in this layer is the main source leading to soil salinization.

\section{Strategies for action in the Yanqi basin}

Several options to manage the Yanqi basin in a more sustainable way exist. Reducing the irrigated area, improving the efficiency of the irrigation system or planting salt tolerant crops would help to save water and to increase the depth to groundwater. One of the most promising options is the substitution of irrigation water by groundwater. If a part of the irrigation water directly drawn from the rivers is substituted by river water pumped indirectly from the aquifer, the groundwater table will drop and the process of salinization will be slowed down. Groundwater is hardly used today, as due to energy requirements it is more 
expensive than surface water. However, if the water table can be kept low by pumping groundwater, the conservation of soil for continued agricultural use along the Kaidu River might strike the balance with a higher price of water. The major decision variable to steer the system into a desirable state without reducing the irrigated area is the ratio of irrigation water drawn directly from the river to the water drawn indirectly from the river by pumping groundwater.

Even though pumping groundwater can potentially reduce phreatic evaporation and increase the available water resources downstream, abstraction from the second layer does include a risk. If the groundwater table in the first layer is lowered due to the abstraction of water in the second layer, there must be a water flux infiltrating from the (saline) first layer to the second layer. The infiltrating, saline water of the first layer will inevitably increase the salt concentration in the second layer. To assess the feasibility of groundwater abstraction, a hydrologic model was set up simulating groundwater, surface water and the coupling between them. Two questions are clarified with the model: (1) how large is the potential to reduce phreatic evaporation, and (2) how will the salt concentration in irrigation water, the first and the second aquifer layer develop?

\section{Modelling approaches}

\subsection{Model setup and results}

The simplest way to estimate the water and salt fluxes of the Yanqi basin is to set up a box model. Even though such a modelling approach is too simple to assess the feasibility of abstracting groundwater, it demonstrates that the salt concentration of a system will increase until the flux of outgoing salt equals the flux of incoming salt and allows the identification of the key-processes determining the long term sustainability of the planned groundwater abstraction. However, the boxmodel does not allow to determine in which specific regions the groundwater table is close to the surface and where the risk of triggering the salinity problem is high.

To assess these parameters realistically, a distributed hydrological model has to be set up. A considerable amount of input data is required to construct and verify such a distributed model. A digital terrain model was calculated on the basis of radar images and verified by 60 D-GPS measurements on the ground. Recharge rates were quantified on the basis of the distribution of evapotranspiration as well as the documented amount of irrigation water applied. The distribution of evapotranspiration was be calculated on the basis of NOAAAVHRR data (according to Roerink et al., [11]). The relation between the groundwater table and phreatic evaporation was quantified by calculating phreatic evaporation on the basis of the distribution of stable isotopes in the unsaturated zone (Barnes and Allison [1]). The information required to model the surface hydrology comprises the structure of Bostan Lake as well as the basic geometry of the rivers and drainage channels. Besides all the remote sensing data used, point measurements such as the depth to groundwater at boreholes, the 
discharge of the drainage net or the discharge of the rivers at several measurement stations were applied. The construction and verification of the model is discussed in detail by Brunner [2].

Three different types of steady state models were set up with the calibrated model: a steady state model representing the average conditions for the period of 1990-1999, a zero irrigation scenario analyzing the water fluxes if no irrigation takes place, as well as a model simulating the effect of groundwater abstraction for irrigation purposes. The zero-irrigation scenario clarified where phreatic evaporation is caused by irrigation and where it occurs naturally. High groundwater tables are found in many areas even without irrigation. The largest areas are the salt marshes along the lake shore. The comparison between the steady state simulations and the zero-irrigation scenario revealed that around $50 \%$ of phreatic evaporation is related to irrigation. The calculated distribution of phreatic evaporation is shown in figure 2. The pumping scenario showed that every $\mathrm{m}^{3}$ of river water substituted by groundwater increases the available downstream resources by at least $0.75 \mathrm{~m}^{3}$ and reduces the salinized area by 50 $\mathrm{km}^{2}$. The reduction of phreatic evaporation is exactly the amount of water additionally available for the downstream systems.

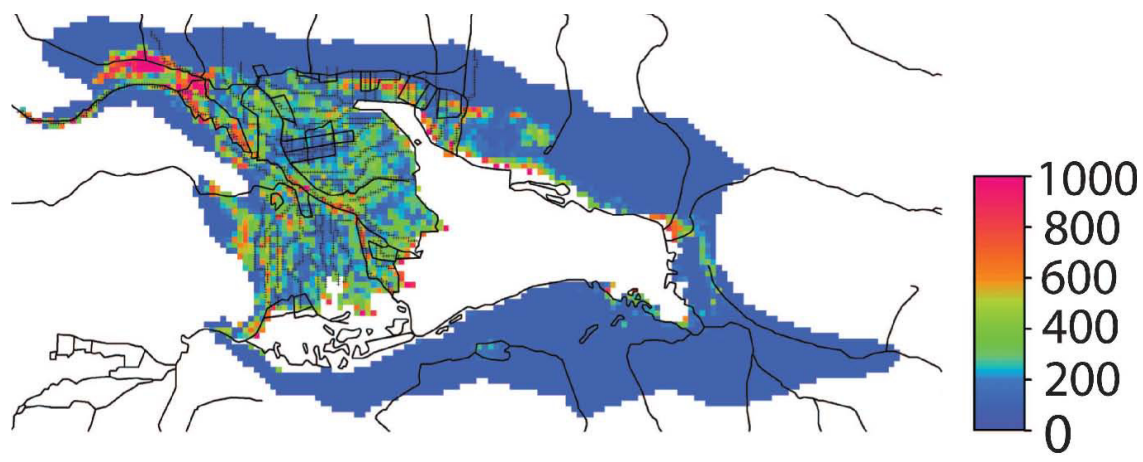

Figure 2: $\quad$ Phreatic evaporation $\left[\mathrm{mma}^{-1}\right]$ calculated by the calibrated model.

The examination of the exchange rates between the first and second aquifer layer along the lake (for the zero irrigation scenario, the pumping scenario and the calibrated model simulating the situation between 1990-1999) showed that only a small portion of water evaporating in the salt marshes is from the lake, while the major portion comes from the second aquifer layer. This mechanism demonstrates how nature evaporates water in the upstream without increasing the salt concentration in the downstream: by transporting the salt accumulated by evaporation to a zone where it is deposited in the long term. Even though phreatic evaporation along the lake shore is not very high, it constantly removes salt from the system. Salt transported to this area is effectively removed from the system because the only major output flux of water in this area is evaporation. The salts accumulating therefore cannot easily be re-mobilized, in contrast to salt removed by the drainage network which will contribute to the salt load of the downstream systems. However, the drainage net remains very important for the 
salt balance of the system. The steady state model revealed that the amount of salt removed through the drainage system is of the same magnitude as the salt stored around the lake. A deactivation of the drainage net would therefore lead to a significant increase of the salt concentration. In order to prevent the deactivation of the drainage net as a consequence of the lowered groundwater table, pumps should exclusively be installed in areas where the drainage net is insufficient and where irrigation has induced phreatic evaporation. Such areas can easily be identified by subtracting the map of phreatic evaporation of the calibrated model from the distribution of phreatic evaporation in the zeroirrigation scenario.

Besides steady state simulations, a transient model was set up to examine how phreatic evaporation is reduced in time. These simulations showed that the reduction of phreatic evaporation is reached within only a few years. Besides the changes in the overall water balance, the simulations could show that the flow of water from the second to the first layer along the lake is still maintained, even if groundwater is pumped from the second layer. This flux is an important sink of salt. The water flux from the second to the first layer in the pumping scenario is illustrated in figure 3 .

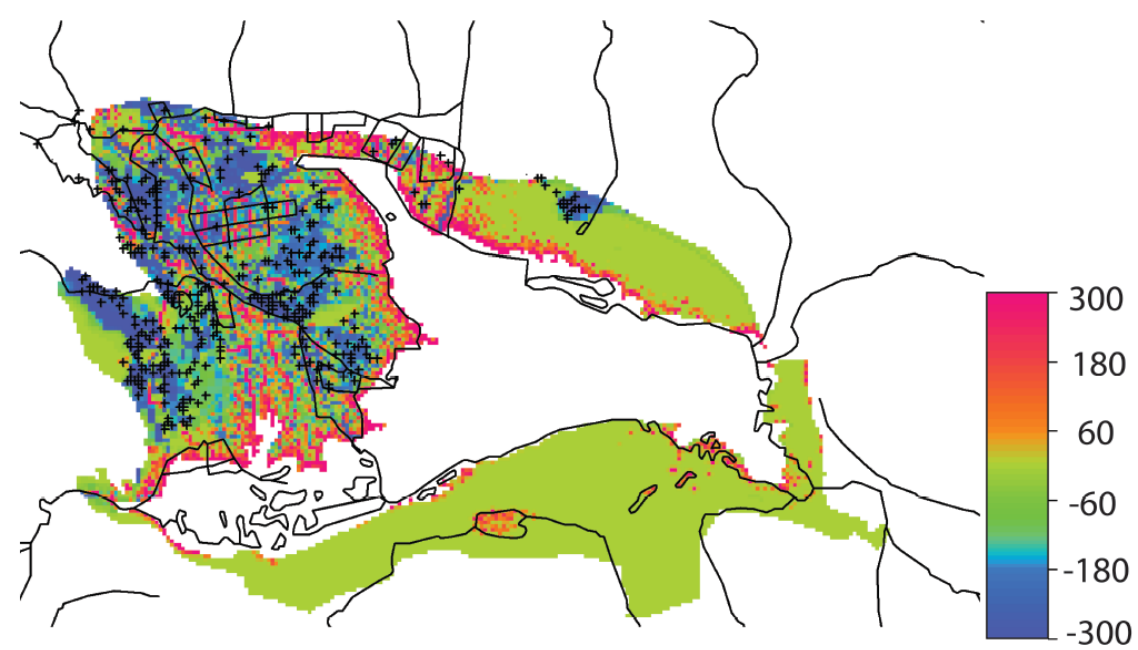

Figure 3: Vertical exchange $\left[\mathrm{m}^{3} \mathrm{~d}^{-1}\right]$ between the second and the first aquifer layer for the confined area in the steady state pumping scenario. Positive numbers indicate a water flux from the second to the first layer. Crosses indicate that a pump is abstracting water. In the areas where no pumps have been installed, the drainage net is still active and an upward flux into the first layer is observed.

\subsection{Estimating the resulting salt concentration of the aquifer system}

In order to estimate the resulting salt concentration of the first and second aquifer layer as well as of the irrigation water, a box model describing the salt fluxes between the first and second aquifer layer was set up. The water fluxes 
(calculated by using the pumping scenario) between these two compartments were used to calculate the changes of the salt concentration within the two layers as well as the resulting steady state concentrations. This model is illustrated in figure 4.

The following considerations and assumptions were made: In the salt balance for the first aquifer layer, only the salt flux from the second to the first layer within the irrigated area is considered. These fluxes are not removed from the system and therefore are considered in the salt balance. On the other hand, salt deposited along the lake's vicinity is not easily re-mobilized and therefore cannot be returned into the irrigated system. The portion of the saltflux $\mathrm{Q}_{21} \mathrm{c}_{2}$ considered in the salt balance is defined as $\eta$.

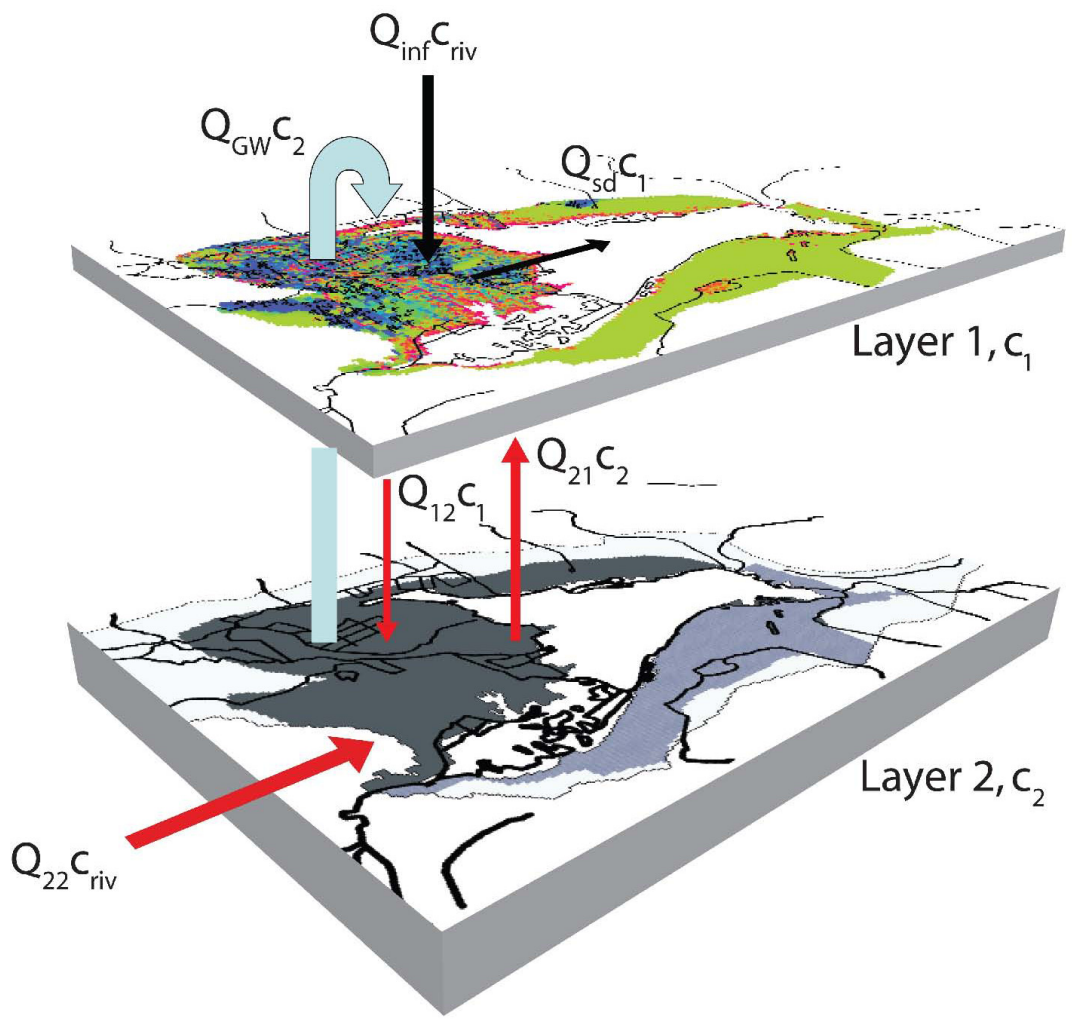

Figure 4: $\quad$ Salt fluxes for the confined area between first and second model layer. The system boundary to calculate the salt balance is plotted in dark gray (see second layer).

It is also assumed that the concentration of the drainage water equals the salt concentration of the first layer. Horizontal fluxes in the first aquifer layer are neglected. The horizontal hydraulic conductivity of the first layer is so small that these fluxes amount to less than $1 \%$ of the infiltration rate in the pumping 
scenario. Moreover, the exchange with the third layer is neglected. The netexchange rate of water between the second and third layer is less than $3 \%$ of the incoming water fluxes (in all scenarios). Moreover, the lateral boundary fluxes of the second layer are very small (less than $2 \%$ of the outgoing water fluxes in all scenarios) and are therefore not taken into account. The last assumption is that the concentration of water flowing from the unconfined area of the second layer to the confined area of the second layer equals the concentration of the river water. This is to be expected as the only source of water in the unconfined area of the second layer is the Kaidu River. The analysis of water samples of the second layer showed that this assumption is justified. Based on these assumptions, the salt balance for layer 1 can be expressed by:

$$
c_{2} \cdot\left(Q_{G W}+\eta \cdot Q_{21}\right)-c_{1} \cdot\left(Q_{s d}+Q_{12}\right)+Q_{\text {inf }} \cdot c_{r i v}=V_{1} \frac{d c_{1}}{d t}
$$

$Q_{G W}$ is the amount of water pumped from the second layer, $Q_{\text {inf }}$ is the sum of water diverted for irrigation and infiltrating directly from the rivers into the system. $Q_{s d}$ is the amount of water removed by surface drainage. $c_{1}$ is the salt concentration in the first layer and $\mathrm{c}_{2}$ the salt concentration of the second layer, as $c_{r i v}$ is the concentration of the river water. $Q_{12}$ is defined as the water flux from the first to the second layer, $Q_{21}$ the water flux from the second to the first layer. $\mathrm{V}_{1}$ is the aquifer volume (taking the porosity into account). For layer 2, the salt balance is given by:

$$
V_{2} \cdot \frac{d c_{2}}{d t}=c_{1} \cdot Q_{12}+Q_{22} \cdot c_{r i v}-c_{2} \cdot\left(Q_{G W}+Q_{21}\right)
$$

$Q_{22}$ is the flux of water from the unconfined area of the second layer to the confined area of the second layer. The concentration of the irrigation water consisting of a mix between ground-and surface water can be calculated by the following equation:

$$
c_{\text {mix }}=\frac{\left(Q_{G W} \cdot c_{2}+Q_{d i v} \cdot c_{r i v}\right)}{\left(Q_{G W}+Q_{d i v}\right)}
$$

with $Q_{\text {div }}$ being the amount of river water applied to irrigation. The steady state concentration in the first layer is given by:

$$
c_{1}=-\frac{c_{r i v}\left(Q_{22} \cdot Q_{G W}+Q_{G W} \cdot Q_{d i v}+Q_{21} \cdot Q_{d i v}+Q_{22} \cdot \eta \cdot Q_{21}\right)}{\left(Q_{12} \cdot \eta \cdot Q_{21}-Q_{s d} \cdot Q_{G W}-Q_{s d} \cdot Q_{21}-Q_{12} \cdot Q_{21}\right)}
$$

and $\mathrm{c}_{2}$ by:

$$
c_{2}=\frac{c_{r i v}\left(Q_{12} \cdot Q_{22}+Q_{s d} \cdot Q_{22}+Q_{12} \cdot Q_{d i v}\right)}{\left(Q_{12} \cdot \eta \cdot Q_{21}-Q_{s d} \cdot Q_{G W}-Q_{s d} \cdot Q_{21}-Q_{12} \cdot Q_{21}\right)}
$$


The water fluxes required to evaluate $c_{1}$ and $c_{2}$ were determined with the model (steady state pumping scenario). The initial concentration of the first layer is set to $10 \mathrm{~g} \mathrm{l}^{-1}$. This is of the same magnitude as the salt concentration in the drainage water.

The development of the salt concentrations within the confined area of the first and second aquifer layers and in the irrigation water is presented in figure 5. The resulting steady-state concentration for the irrigation water is $0.57 \mathrm{~g} \mathrm{l}^{-1}$, for the first layer $0.91 \mathrm{~g} \mathrm{l}^{-1}$ and for the second layer $0.76 \mathrm{~g}^{-1}$ respectively. The concentration of the irrigation water $\left(c_{m i x}\right)$ increases to a maximum of $0.81 \mathrm{~g} \mathrm{l}^{-1}$. This maximum is reached after 20 years. Even though the maximum concentration is by a factor of 2 higher than the concentration of the river water, the quality is still sufficient to irrigate crops. In the long run, concentrations decrease. This is due to the fact that the amount of salt stored in the first layer is gradually removed from the system, either to the downstream or to the salt crust along the lake.

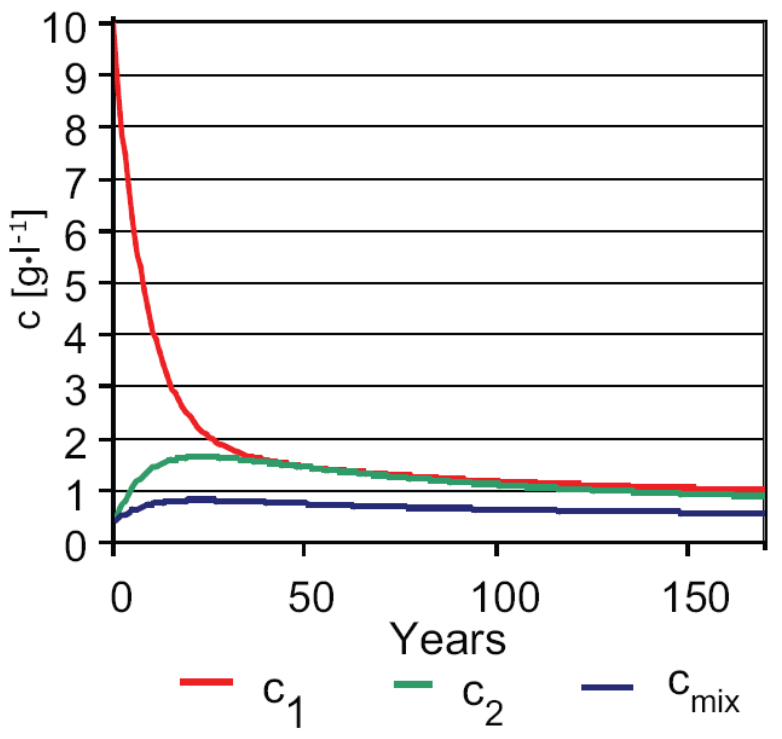

Figure 5: Development in time of the salt concentration of the irrigation water and of water in the first and second aquifer layer.

\section{Conclusions}

The overall conclusion of this modelling approach is that the productivity of the agriculture can be maintained in the Yanqi basin and that the available resources for the downstream systems can be increased by substituting a part of the irrigation water drawn from the river by pumped groundwater. Besides the creation of the new infrastructure for groundwater abstraction, the old 
infrastructure of the drainage network must be maintained. Owing to the output fluxes through the drainage network, the steady state salt concentration of the system remains below a critical level. The drainage network accounts for up to $50 \%$ of the output salt fluxes and therefore significantly reduces the steady state salt concentration of the first and second aquifer layers as well as the quality of the irrigation water.

Besides pumping groundwater, an increase of the irrigation channel efficiency is highly recommended. Even though only $13 \mathrm{~m}^{3} \mathrm{~s}^{-1}$ of water are consumed by plants, the available water resources for the downstream systems are reduced by $23 \mathrm{~m}^{3} \mathrm{~s}^{-1}$. This loss contributes to phreatic evaporation. Installing pumps close to the fields where the water is applied for irrigation will reduce the channel losses and again will contribute to the downstream resources.

Considering the large amount of salt stored in the soil column as well as the high groundwater tables in some areas of the basin, it becomes clear that sustainable irrigation in the Yanqi basin is indeed a difficult undertaking. It is therefore recommended not to increase the irrigated area. This recommendation can be relaxed only if the total amount of water applied for irrigation is kept at the present level by increasing the efficiency of the irrigation system. If new fields are claimed for irrigation, they should not be located in areas where the groundwater table is already high.

\section{References}

[1] Barnes, C. J., Allison, G. B., 1988. Tracing of water-movement in the unsaturated zone using stable isotopes of hydrogen and oxygen. Journal of Hydrology 100 (1-3), 143-176.

[2] Brunner, P., 2005. Sustainable agriculture in the Yanqi basin, China. Ph.D. thesis, PhD Thesis ETH Zurich No.16210, ISBN 3-906445-26-7. URL: http://e-collection.ethbib.ethz.ch/show?type=diss\&nr $=16210$

[3] Dong, X., Jiang, T., Jiang, H., 2001. Study on the pattern of water resources utilisation and environmental conservation of Yanqi basin. In: Li, G. (Ed.), Development, Planning and Management of Surface and Groundwater Resources. Vol. A of IAHR congress proceedings. Tsinghua University Press, Beijing, China, pp. 333-340.

[4] Hillel, D., 1987. The efficient use of water in irrigation: Principles and practices for improving irrigation in arid and semi-arid regions. World Bank, Washington D.C.

[5] Hillel, D., 1990. Out of the Earth: Civilization and the Life of the Soil. Free Press, New York.

[6] Hillel, D., 2000. Salinity management for sustainable irrigation: Integrating Science, Environment and Economics. World Bank, Washington D.C.

[7] Jakeman, A. J., Nix, H. A., Ghassemi, F., 1995. Salinisation of Land and Water Resources: Human Causes, Extent and Management. CAB International, Wallingford Oxon. 
[8] Lin, A., Fu, B., Kano, K., Maruyama, T., Guo, J., 2002. Late quaternary rightlateral displacement along active faults in the Yanqi basin, southeastern Tian Shan, northwest China. Tectonophysics 354 (3-4), 157178 .

[9] Rhoades, J. D., Kandiah, A., Mashali, A. M., 1992. The use of saline waters for crop production. Food and Agriculture Organization of the United Nations, Rome.

[10] Richards, L., 1954. Diagnosis and Improvement of Saline and Alkali Soils. U.S. Department of Agriculture. Agriculture Handbook. no. 60. USSalinityLab, Washington DC.

[11] Roerink, G. J., Su, Z., Menenti, M., 2000. S-SEBI: A simple remote sensing algorithm to estimate the surface energy balance. Physics and Chemistry of the Earth Part B-Hydrology Oceans and Atmosphere 25 (2), 147-157. 